\title{
A CONCEPTUAL MODEL FOR VIRTUAL BREEDING ENVIRONMENTS VALUE SYSTEMS
}

\author{
David Romero', Nathalie Galeano', Arturo Molina ${ }^{2}$ \\ ${ }^{l}$ CYDIT - ITESM Campus Monterrey, Monterrey, MEXICO \\ david.romero.diaz@gmail.com,ngaleano@itesm.mx \\ ${ }^{2}$ VIYD - ITESM Campus Monterrey, Monterrey, MEXICO \\ armolina@itesm.mx
}

\begin{abstract}
Virtual Breeding Environments (VBEs) represent networks of disperse organisations, that will exploit specific collaboration opportunities through the creation of Virtual Organisations (VOs) supported by information and communication technologies (ICTs). This type of Collaborative Networked Organisation (CNO) should be able to generate different types of values (economical, social, cultural, etc) to its members and stakeholders. In this sense, the definition of a value system represents a useful network management tool for the recognition, measurement and configuration of value generation objects and activities inside the network. This paper presents a conceptual model that integrates the different value generation objects, from the different stakeholders, to describe a VBE value system that supports managerial activities in the network such as value co-creation and performance measurement.
\end{abstract}

\section{INTRODUCTION}

Virtual Organization Breeding Environments (VBEs) are long-term cluster/associations of autonomous, geographically dispersed and heterogeneous organizations. The VBE aims to prepare its member's organizations and support institutions, and enhance their readiness for potential involvement in collaboration opportunity-based Virtual Organizations. A Virtual Organization (VO) is defined as a temporally association of (legally) independent organizations that come together to share skills and resources to achieve a common goal, such as preparing a proposal (or a bid), or jointly performing the tasks needed to satisfy a market/society opportunity by coproducing products/services for the customer, and whose cooperation is supported by computer networks (Camarinha-Matos and Afsarmanesh, 2006).

This paper will present a conceptual model for defining a VBE value system considering the main elements that should be identified in order to manage different strategies to co-create value for the customers and wealth for all VBE stakeholders. A proposal for define a performance measurement system for the evaluation of value creation process in a VBE is also presented in this article.

Romero, D., Galcano, N., Molina, A., 2007, in IFIP International Federation for Information Processing, Volume 243, Establishing the Foundation of Collaborative Networks; eds. Camarinha-Matos, L., Afsarmancsh, H., Novais, P., Analide, C.; (Boston: Springer), pp. 43-52. 


\section{BASIC CONCEPTS ON VALUE SYSTEMS}

For a complete definition of a Value System it is important to understand the term value, the types of values that are involved in a value system, and how these values can be measured and evaluated.

Value: Two scientific disciplines that have been studying this concept for several years: economy and sociology. Each discipline has developed a different concept of value. On one hand, economists define value as "the worth of a product or service (often measured in terms of money) to someone", and on the other hand, sociologists define value as "the shared beliefs on moral/ethical principles that govern the behaviour of individuals and organisations in society" (Macedo et al, 2006).

For the purpose of this paper, economic values will be understood in relation to the production factors: land, labour, capital and knowledge, involved in value creation, considering tangible and intangible perceptions of what is valuable. Furthermore, ethical values will be comprehended as the set of accepted conduct standards that regulate the behaviour of organisations in value exchange among them and their customers in the market.

Value systems: underline the value-creation system through which an organisation or group of organisations produce value. Therefore, a value system is the identification, structure and measurement of a set of values that an actor holds, exchanges and creates for specific purposes. Moreover, value systems are based on the notion that "each product/service offered requires a set of activities carried out by a number of actors forming a value-creation system, that use tangible and intangible resources for creating value for customers" (Parolini, 1999).

Value systems are important in terms of regulation role for guarantee social cohesion and understanding between actors and their transactional mechanisms to assure an equality utility in value exchange; value systems are also important in terms of performance measurement to monitor how different actors, activities and resources work together to co-produce value (Afsarmanesh and Camarinha-Matos, 2005).

Performance Measurement: Measuring value creation in a value system requires a performance management cycle that plan, sets expectations and continually monitors performance.

Performance measurement in value systems is usually focused on economic values, including tangible and intangible resources, involved in a value creation process. The purpose of performance measurement is to assess whether progress is being made towards the desire goals and whether activities are performed efficiently to create value. Performance measurement serves to identify how actors are carrying out their activities and using their resources in a value-creation system to deliver a product/service to the customer.

VBE Value System: Form the definitions presented we can derive a definition of a VBE Value System as follows: The Value System is the identification, structure and measurement of a set of values that a VBE creates, holds, and exchanges. Since value is multidimensional, the Value System in a VBE should consider economic, ethical and cultural values; it also considers the identification and measurement of what is valuable for all VBE stakeholders. 


\section{VBE VALUE SYSTEM CONCEPTUAL MODEL}

The main purpose of the Value System is to identify the value added of the VBE, which can be measured, through the Performance Measurement System, in terms of tangible (economic benefits productivity related) and intangible values or benefits (strategic, social, among others). Value systems are a useful network management tool for the recognition, measurement and configuration of value generation objects and activities inside the breeding environment.

Therefore, VBE value systems should be able to recognize how their different stakeholders such as members, support institutions, administrators, opportunity brokers, VO planners and VO coordinators combine their knowledge, resources and activities in a value-creation system capable of creating different types of values, for instance: economical and ethical values.

\subsection{VBE Value System and its Elements}

Three important elements integrate the conceptual model proposed for a VBE value system (Figure 1): first, the value generation objects as the different types of capitals hold by the breeding environment itself and by its members; second, the performance measurement system evaluating the value co-creation process; and third, the ethical values guiding the value exchange among actors (customers and stakeholders). Additionally, VBE value system elements support the trust building process among actors by providing an inventory of the value generation objects inside the breeding environment, and also through an ethical code as a set of functional rules to assure the ethical viability of business operation.

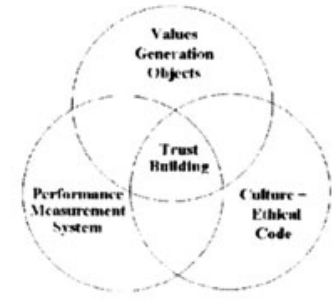

Figure 1 - VBE Value System Model

Figure 2 presents the relationship among the first two VBE value system elements: the value generation objects and the performance measurement system. The VBE value system combines the value generation objects (detailed in section 3.2) represented by financial, intellectual and social capitals of VBE members with the value generation objects of the breeding environment itself (also known as VBE platform) to co-create value in the development of collaborative business opportunities. Furthermore, value co-creation processes is measured to encompass the assessment of performance and results achieved by VBE actors; five dimensions are defined: financial, productivity, strategic, social and trust. The performance measurement system (detailed in section 3.3) evaluate at different levels: VBE members, VOs and the VBE itself. Additionally, some monitoring and reporting tools could be based on actual valuation models such as Balance Scorecard model (BSC) or European Foundation for Quality Management Model (EFQM). 
Finally according to the results of the performance indicators, incentives and sanctions can be identified for each VBE member.

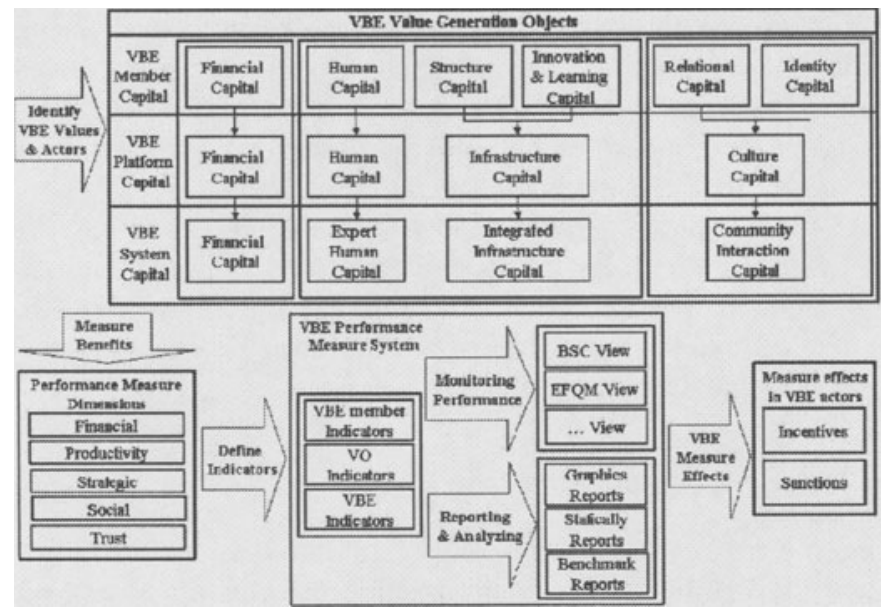

Figure 2 - Relationship between VBE Value Generation Objects and VBE Performance Measurement System

\subsection{VBE Value Generation Objects: Capitals in Organisations}

Value Generation Objects, or Capitals, identify the main values and benefits, such as economic success and other types of valuable benefits (productivity, strategic, social, trust) for breeding environment stakeholders. VBE members participate in the breeding environment by converting their competences and knowledge into tangible and intangible deliverables that are valuable for other VBE members, stakeholders and VO customers. In a successful breeding environment every VBE member contributes and receives value in ways that sustain their own success and the success of the VBE as a whole system.

The value generation objects in a VBE are identified as the sum of:

- VBE member's value generation objects that represent the capitals that each member has and generates by itself.

- VBE platform value generation objects that represents the methodologies, ICT and supporting tools for the breeding environment. This platform by itself offers different types of values.

The total VBE system value generation objects are constituted by the synergy of the capitals of each VBE members and capitals of the VBE platform.

\begin{tabular}{|c|c|c|c|c|c|c|}
\hline \multicolumn{7}{|c|}{ VBE, Vulue Genernation Objects } \\
\hline $\begin{array}{l}\text { VBE } \\
\text { Member } \\
\text { Capital }\end{array}$ & $\begin{array}{c}\text { Financial } \\
\text { Capital }\end{array}$ & $\begin{array}{l}\text { Human } \\
\text { Capital }\end{array}$ & $\begin{array}{c}\text { Structure } \\
\text { Capital }\end{array}$ & $\begin{array}{c}\text { Innovation } \\
\text { \& Leaming } \\
\text { Capital }\end{array}$ & $\begin{array}{c}\text { Redational } \\
\text { Capital }\end{array}$ & $\begin{array}{l}\text { Identity } \\
\text { Capital }\end{array}$ \\
\hline \multirow{2}{*}{$\begin{array}{l}\text { VBE } \\
\text { Pletform } \\
\text { Capital }\end{array}$} & $t$ & $t$ & \multirow{2}{*}{\multicolumn{2}{|c|}{$\begin{array}{c}\text { Infrastructure } \\
\text { Capital }\end{array}$}} & \multicolumn{2}{|c|}{7} \\
\hline & $\begin{array}{c}\text { Financial } \\
\text { Capital }\end{array}$ & $\begin{array}{l}\text { Human } \\
\text { Capital }\end{array}$ & & & & \\
\hline \multirow[b]{2}{*}{$\begin{array}{c}\text { VBE } \\
\text { System } \\
\text { Capital }\end{array}$} & 5 & $\frac{1}{7}$ & \multicolumn{2}{|r|}{$i$} & \multicolumn{2}{|c|}{7} \\
\hline & $\begin{array}{c}\text { Financial } \\
\text { Cupital }\end{array}$ & $\begin{array}{l}\text { Expert } \\
\text { Aluman } \\
\text { Capital }\end{array}$ & \multicolumn{2}{|c|}{$\begin{array}{c}\text { Integrated } \\
\text { Infrastructure } \\
\text { Capital }\end{array}$} & \multicolumn{2}{|c|}{$\begin{array}{c}\text { Community } \\
\text { Interaction } \\
\text { Capital }\end{array}$} \\
\hline
\end{tabular}

Figure 3 - VBE Value Generation Model 
VBE value generation objects or capitals may fall into several categories; two major types of values are identified in organisations: tangible and intangible values. Three types of capitals can be identified in organisations: financial, intellectual and social capitals. The financial capital is related to all physical assets (that generates tangible values), meanwhile intellectual and social capitals are related to all the knowledge and relational based assets (that generates intangible and tangible values).

The components of VBE value generation model are presented in Tables 1 to 3:

\section{Table 1 - VBE Member Capitals}

\begin{tabular}{|c|c|}
\hline & $\begin{array}{l}\text { value. } \\
\text { valution }\end{array}$ \\
\hline $\begin{array}{l}\text { Intellectual Capital: } \\
\text { - Human Capital. Assets of knowledge (explicit or } \\
\text { tacit) of the organisation staff useful to create value } \\
\text { through their competences (skills, talent, capabilities } \\
\text { and knowledge). } \\
\text { - Structure Capital. Knowledge that an organisation } \\
\text { materializes, systematizes and internalizes in form of } \\
\text { physical resources: information and communication } \\
\text { technologies, production technologies, work processes, } \\
\text { management system, and quality standards. } \\
\text { - Innovation \& Learning Capital. The possibility to } \\
\text { maintain the success of an organisation in a long term } \\
\text { by developing or improving competences to increase } \\
\text { and fortify the efficiency of the manufacturing } \\
\text { processes or services development. }\end{array}$ & $\begin{array}{l}\text { Social Capital: } \\
\text { - Relational Capital. It refers to the relations and } \\
\text { logistic channels that an organisation maintains with } \\
\text { his clients, suppliers or other organisations (e.g. } \\
\text { supply chain, collaborative networks, and relations } \\
\text { in the VBE), and the value that these types of } \\
\text { relation generates. } \\
\text { - Identity Capital. It refers to the mix of recognition } \\
\text { and history of the organisation used to influence the } \\
\text { perception and activities of employees, customers } \\
\text { and other organisations. It has the ability to create } \\
\text { the image of vision of the organisation as parts of its } \\
\text { culture. }\end{array}$ \\
\hline
\end{tabular}

Table 2 - VBE Platform Capitals

\begin{tabular}{|l|l|}
\hline $\begin{array}{l}\text { Financial Capital: It refers to the financial resources that a VBE as a Platform uses to achieve objectives (e.g. cash, } \\
\text { insures, bank accounts, physical assets such as tools, equipment, inventories). }\end{array}$ \\
\hline $\begin{array}{l}\text { Intellectual Capital: } \\
\text { - Human Capital. Composed by the VBE }\end{array}$ & $\begin{array}{c}\text { Social Capital: } \\
\text { - Social and Cultural. It refers to the working and } \\
\text { administrator, VO broker, VBE advisor, VBE service } \\
\text { sharing principles of a VBE represented in his } \\
\text { strategies, philosophy, culture and ethical code } \\
\text { provider and VBE ontology provider with their skills, } \\
\text { talent, capabilities and knowledge. }\end{array}$ \\
$\begin{array}{l}\text { - Infrastructure Capital. It includes the technologies } \\
\text { (e-catalogue, value and performance measure systems, }\end{array}$ & \\
and VBE management system), methods and processes \\
(e-brokering, trust building and management, VO \\
creation process, VBE administration) and physical \\
resources that support the VBE.
\end{tabular}

Table 3 - VBE System Capitals

\begin{tabular}{|c|c|}
\hline \multicolumn{2}{|c|}{$\begin{array}{l}\text { Financial Capital: It refers to the sum of the financial capital of the VBE members that will be shared in the VBE } \\
\text { and VBE platform. }\end{array}$} \\
\hline $\begin{array}{l}\text { Intellectual Capital: } \\
\text { - Expert Human Capital. It is the result of sharing and } \\
\text { combining the Human Capital competences (skills, } \\
\text { talent, capabilities and knowledge) of the VBE } \\
\text { members' staff with other VBE member's or VBE } \\
\text { staff. This will lead to conform expert teams able to } \\
\text { increment the VBE actors capacity of using } \\
\text { knowledge (know-how) to common objectives (e.g. } \\
\text { add value to a product/process). } \\
\text { - Integrated Infrastructure Capital. It is the result of } \\
\text { sharing and combining resources (e.g. technologic and } \\
\text { financial resources) between VBE members to } \\
\text { increment their capacity to develop new products or } \\
\text { services. }\end{array}$ & $\begin{array}{l}\text { Social Capital: } \\
\text { - Community Interaction Capital. It refers to the } \\
\text { VBE strategies focus on the exploitation of VBE } \\
\text { members' relations and logistics channels. These } \\
\text { strategies according to the changes and necessities } \\
\text { of the market to create competitive advantages. } \\
\text { Also to the relations and working \& sharing } \\
\text { principles of a VBE and their VBE members that } \\
\text { create a moral responsibility, positive intentions, } \\
\text { understanding, respect and equity between the VBE } \\
\text { and VBE members in collaborative opportunities. }\end{array}$ \\
\hline
\end{tabular}




\subsection{Performance Measurement System}

VBE Performance Measurement System is formed by a set of indicators that translate the value co-creation process into "numbers". The ability to quantify VBE results is the first step for improving the overall performance of the VBE members and therefore the value co-creation process in the breeding environment.

The indicators defined in the performance measurement system should be the base to define and create incentives and sanctions in the breeding environment.

The performance measurement system provide the strategic information to VBE members about how VBE platform capitals and VBE member's capitals work together to co-produce value. The performance measurement system will permit to the VBE actors and mainly the VBE members to calculate the value of their relationships inside the breeding environment, and this information will be useful for taking the right and strategic collaborative business decisions. The breeding environment indicator system will make easier to monitor the progress of VBE value co-creation.

To monitor the VBE performance, the performance measurement system the Balance Scorecard (BSC) model can be used. BSC (Kaplan and Norton, 2004) is a model that shows the balance between the present and the future of an organisation, including its internal and external perspectives. It permits the organisations to analyze their final results (financial and non financial) and at the same time to monitor the progress of the construction of intangible assets for which the organisation needs to create more value. The measures depend on the indicators, which need to be aligned to the activities originated by the organisation strategy.

Figure 4 presents a VBE generic strategic map based on the BSC concepts, as a proposal for supporting the performance measurement system in a breeding environment. It is important to mention that depending on the focus, strategy and the main goals of each VBE this map should change accordingly.

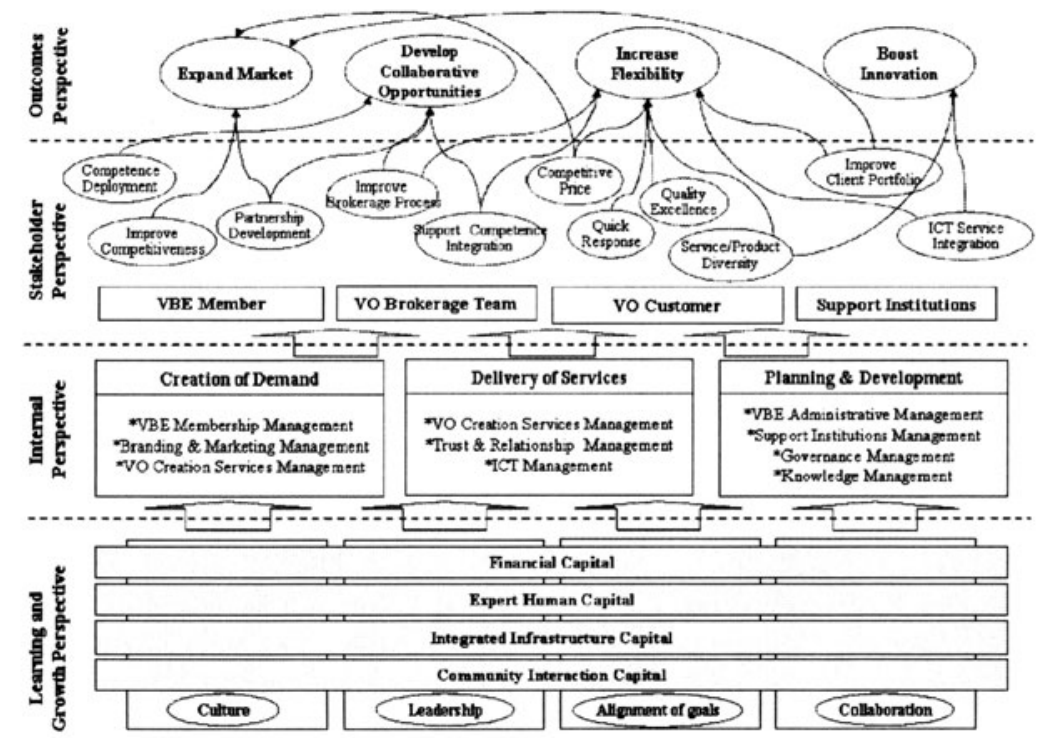

Figure 4 - VBE Generic Strategic Map based on BSC model 
Four perspectives can be identified from the VBE generic strategic map:

- Outcomes Perspective: Constitute the final outcomes that are the result of the actions taken by the breeding environment. The measurement of outcomes indicates how the strategies have lead to results for the organisation. Four main outcomes are generally expected in profit-driven VBEs: Expand market for its members, support the exploitation and development of collaborative opportunities, boost innovation, and increase flexibility of its members.

- Stakeholder Perspective: In this perspective, the organisation identifies the market segments in which it wants to compete. Some of the most common indicators for this perspective are: the VBE stakeholders' satisfaction, and retention, number of VBE new stakeholders and collaborative opportunities. In the VBE there are four main stakeholders: VBE members, VO brokerage team (opportunity broker, VO planner or integrator and VO coordinator), VO customer and support institutions.

- Internal Processes Perspective: In this perspective the processes which must be precisely executed and improved continuously are identified. These processes help the VBE to develop a value proposition for: obtain and maintain members, create VOs, and satisfy the expectations of all its stakeholders. Main processes in a VBE include: 1) those related with the delivery of services of the VBE, such as: VO creation services management, trust and relationship management, and ICT management; 2) those related with the creation of demand in terms of collaboration opportunities exploitation, such as: VBE members management, branding and marketing management, and VO services management; and 3) those related with the planning and development of the VBE such as: VBE administrative management, support institutions management, governance management, and knowledge management.

- Leaning and Growth Perspective: It refers to the infrastructure that the VBE must construct to create growth in long term. This infrastructure is supported by the value generation objects that are present in a VBE, including: VBE community interaction capital, VBE integrated infrastructure capital, VBE expert human capital and VBE financial capital. All of them, supported by the VBE culture, leadership, collaboration and alignment of goals among the VBE and its members.

The monitoring of Performance Indicators in a VBE can be guided by this model. Tables 4 to 6 show a proposal that aligns main VBE indicators previously proposed in each perspective.

Table 4 - Example of Outcome Perspective Indicators

\begin{tabular}{|l|l|}
\hline \multicolumn{1}{|c|}{ Elements } & \multicolumn{1}{c|}{ Goal Indicators } \\
\hline Expand Market & - Annual VBE sales \\
\hline Develop Collaborative Opportunity & - Annual number of VOs created \\
\hline Boost Innovation & - Annual number of new products/services developed in the VBE \\
\hline Increase Flexibility & - Annual number of products/services developed in the VBE \\
& - Number of members in the VBE \\
& - Number of services available for VBE members \\
\hline
\end{tabular}


Table 5 - Example of Stakeholders Perspective Indicators

\begin{tabular}{|c|c|c|}
\hline \multicolumn{2}{|r|}{ Elements } & Indicators \\
\hline \multirow{3}{*}{ 嶳总 } & Competence deployment & $\begin{array}{l}\text { - Number of services available for the VBE members } \\
\text { - Number of competencies available in the VBE }\end{array}$ \\
\hline & Partnership development & $\begin{array}{l}\text { - Annual incomes to VBE as result of VOs creation } \\
\text { - Annual number of business/collaborative opportunities identified } \\
\end{array}$ \\
\hline & Improve competitiveness & - Annual number of new products/services developed in the VBE \\
\hline \multirow{2}{*}{ ○造 } & Improve brokerage process & $\begin{array}{l}\text { - Annual \% of business/collaborative opportunities answered ove } \\
\text { the opportunities identified }\end{array}$ \\
\hline & Support competences integration & - Average number of participations of a VBE member in VOs \\
\hline \multirow{4}{*}{ ○ 产 } & Competitive price & - Customer satisfaction evaluation \\
\hline & Quality excellence & $\begin{array}{l}\text { - Customer satisfaction evaluation } \\
\text { - \% collaborative opportunities rejected by the customer for quality } \\
\text { reasons }\end{array}$ \\
\hline & Quick Response & - \% collaborative opportunities attended on time \\
\hline & Service/product diversity & $\begin{array}{l}\text { - Annual number of patents registered } \\
\text { - Annual number of new products/services developed in the VBE } \\
\text { - Annual investment in research \& development }\end{array}$ \\
\hline \multirow{2}{*}{ 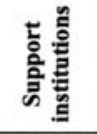 } & Improve client portfolio & - Number of members in the VBE \\
\hline & ICT services integration & $\begin{array}{l}\text { - Number of services offered to VBE members } \\
\text { - Annual number of new services developed for VBE members }\end{array}$ \\
\hline
\end{tabular}

Table 6 - Example of Internal Perspective Indicators

\begin{tabular}{|c|c|}
\hline Elements & Internal Indicators \\
\hline \multirow{3}{*}{$\begin{array}{l}\text { Strategic and Marketing } \\
\text { Management }\end{array}$} & - Annual investment in marketing \& branding \\
\hline & - Annual number of business/collaborative opportunities identified \\
\hline & - Level of satisfaction of VO Customers \\
\hline \multirow{3}{*}{ VBE Membership Management } & - Annual number of participations of a VBE member in VOs \\
\hline & - Annual VBE incomes derived from memberships \\
\hline & - Number of competencies available in the VBE \\
\hline \multirow{2}{*}{$\begin{array}{l}\text { VO Creation Services } \\
\text { Management }\end{array}$} & - Annual incomes to VBE as result of VO services offer \\
\hline & - Number of VO creation services available in the VBE \\
\hline Trust Management & - Number of trustable relations in the VBE \\
\hline ICT Management & $\begin{array}{l}\text { - } \% \text { of coverage of services demanded by VBE members } \\
\text { - Annual cost of maintenance of VBE infrastructure }\end{array}$ \\
\hline Governance Management & - Annual number of conflict resolutions in the VBE \\
\hline Knowledge Management & - Number of accesses to the VBE knowledge/ontology sources \\
\hline Support Institution Management & - Number of support institutions in the VBE \\
\hline VBE Accountability Management & - Annual expenses in VBE operation \\
\hline
\end{tabular}

Together with the identification of the indicators in each perspective, its relation among perspectives should be analyzed. This means that there is a direct relation between the internal perspective, stakeholder perspective and outcome perspective indicators. The internal perspective indicators (those that are measured in the VBE business processes) should support the improvement and achievement of goals related with the stakeholder perspective indicators (which are defined according to the stakeholders' interests). In the same way, the stakeholder perspective should support the achievement of goals and improvement of the outcome perspective indicators.

\subsection{VBE ethical values}

The third VBE value system element is the ethical values described in terms of VBE ethical code and culture. 
The VBE members culture (shared values: strategy structure, systems, style, staff and skills) represents the "glue" which holds a breeding environment together. The willingness of potential VBE members to accept and capitalize on new ways of working, including participating in VOs will depend in part on the prevailing organisational culture. The VBE culture can be defined as "the collection of relatively uniform and enduring values, beliefs, customs, traditions and practices that are shared by VBE members, learned by new member's recruits, and transmitted from one generation of members to the next one" (Adapted from Rezgui et al, 2005).

VBE culture derives from basic assumptions of the values held by VBE members which shape breeding environment objectives, structures, and processes, and which are promoted and shared both directly/indirectly through a range of mechanism. While VOs are a temporary structure, its human resources are drawn from different VBE members, each with their own (possible conflicting) cultures. The lack of a shared culture may create difficulties for the effective operation of a VO. This is partly due to reduced opportunities for interaction between employees, particularly face-to-face interaction, which provide opportunities for new employees or VBE members of the VO to learn about e.g. company values, history, and folklore. Asynchronous communications, which are typical of the VO, mitigate the development of sense of community, although the use of synchronous electronic meetings spaces may help to develop a community with sense of shared culture (Adapted from Rezgui et al, 2005).

A good practice that should guide the operation of the VBE is then, the definition of an ethical code that includes some of the culture elements mentioned before. The Institute of Business Ethics in UK defines an ethical code as a "management tool for establishing and articulating the corporate values, responsibilities, obligations, and ethical ambitions of an organisation and the way it functions". It provides guidance to employees and organisations, on how to handle situations which pose take a dilemma between alternative right courses of action, or when faced with pressure to consider right and wrong. Having an ethical code is not enough, however. It can only be effective and practically useful with committed dissemination, implementation, monitoring and embedding at all levels so that behaviour is influenced in the VBE.

\section{CONCLUSIONS}

A VBE Value System includes the following main elements:

- The identification of the value generation objects or capitals that a VBE and its members have,

- The Performance Measurement System, which will measure the value generation and will be the base for define the VBE incentives and sanctions schemas, and

- The definition of its ethical/cultural values, represented in the culture and ethical code.

- A value system is an important managerial tool for a $\mathrm{VBE}$, because a value system:

- Identify the main elements that generate value in a VBE, in order to focus the VBE operation on these elements. 
- Identify the forms of value (measured in terms of capitals) in each VBE member, making them available to combine with other forms of value of other VBE members to create superior forms of value.

- Support improvement of the overall performance of VBEs and VBE members by providing VBE actors with meaningful performances indicators to evaluate and manage their strategies and processes with the objective to achieve their operational and financial goals.

- Identify the capacity in each VBE member to generate meta-value by combing its capitals with other VBE members (VO Creation).

- Identify the total value generated by a VBE, to evaluate the increase or decrease of value in the VBE during its life-cycle, and compare the success of a VBE with other VBEs and other forms of networks.

- Involve social values (behaviour, ethics and culture) with operational performance in order to create a common functioning environment to better respond in business collaboration.

Support the decisions about adding and retreating members by evaluating their performance through a pre-established indicator system.

\section{ACKNOWLEDGMENTS}

The information presented in this document is part of the results of the ECOLEAD Project (European Collaborative Networked Organizations Leadership Initiative), funded by the European Community, FP6 IP 506958. Document D21.4a - "VBE characterization of Value System and Metrics" presents in detail results about this topic.

\section{REFERENCES}

1. Afsarmanesh, H. and Camarinha-Matos, L.M. (2005). A Framework for Management of Virtual Organization Breeding Environments. In L.M. Camarinha-Matos et al (Ed.), Collaborative Networks and their Breeding Environments. International Federation for Information Processing (IFIP), Volume 186 (pp. 35-48). New York: Springer Publisher.

2. Camarinha-Matos, L.M. and Afsarmanesh, H. (2006). Collaborative networks: Value creation in a knowledge society. In K. Wang et al (Ed.). Knowledge Enterprise: Intelligent Strategies in Product Design, Manufacturing and Management. International Federation for Information Processing (IFIP), Volume 207 (pp. 26-40). New York: Springer Publisher.

3. Institute of Business Ethics - UK. Retrieved on March, 2007, from: http://www.ibe.org.uk/ codesofconduct.html

4. Macedo, P., Sapateiro, C., Filipe, J. (2006). Distinct Approaches to Value System in Collaborative Networks Environments. In L.M. et al (Ed.). Network-Centric Collaboration and Supporting Frameworks. International Federation for Information Processing (IFIP), Volume 224 (pp. 111120). Boston: Springer Publisher.

5. Parolini, C. (1999). The Value Net Tool for Competitive Strategy. John Wiley \& Sons Ltd.

6. Rezgui, Y., Wilson, I., Olphert and Damodaran, L. (2005). Socio-Organisational Issues. In L.M. et al (Ed.), Virtual Organisations: Systems and Practices. Springer Science+Busineess Media Inc. 